The authority has considerable experience of nondestructive testing, and has long had a section devoted to it. Techniques used at Harwell include high definition radiography, image convertor systems, ultrasonic micrometry, bore-gauging and quantized recording. These techniques, and others such as the use of magnetic flux and eddy currents, will now be available more widely to British industry. The centre will carry out research to improve testing techniques, and will also act as consultants and advisors to industry. It will co-operate with industry in investigating specific industrial problems. The first head of the centre will be Mr. R. S. Sharp, who worked with the Bristol Aeroplane Company for 14 years before moving to Harwell to set up the section which will form the nucleus of the new centre.

The Ceramics Research Centre is intended to help and encourage industry to make the best possible use of ceramics. Although widely used for industrial processes at high temperatures, ceramics are not well understood. The iron and steel industry uses more ceramics than most, and is likely to be the chief beneficiary if the centre can make radical improvements in manufacture, fabrication or use, but other industries also use ceramics in smaller quantities. Dr. F. J. P. Clarke of the Ceramics Division at Harwell will be the first head of the centre. Initially work will be concentrated on developing refractory oxides, and on methods of producing high quality oxide ceramics and special graphites.

\section{Multiple Access}

THE Atlas Computer Laboratory of the Science Research Council is embarking on an experiment to test the usefulness of multiple access computer systems. According to the Science Research Council, the project will cost $£ 95,000$. By the beginning of 1968 it is planned that there shall be twenty teletype consoles linked to the Atlas computer through an intermediate satellite machine built by the General Electric Co., Ltd. (U.K.). In the planning of the experiment, careful attention is being given to the quality of the system, and the planners are particularly anxious to avoid peripheral troubles of the kind which have occasionally afflicted other multiple access systems-inadequacy of teleprinter links, for example. The satellite computer is intended to take over much of the housekeeping work associated with multiple access systems; experience with Project MAC at the Massachusetts Institute of Technology is said to have shown that roughly a third of the time spent by users of multiple access systems goes on comparatively humdrum activities such as editing and retrieving information. Obviously it is not sensible to bother the big machine with chores like these. In practice the multiple access experiment will have to compete with the other users of the Atlas computer who at present keep that machine more than saturated. (For every job taken on, two are turned away.) The laboratory is co-operating with International Computers and Tabulators, Ltd., in a study of the habits of computer users when multiple access is available. Among the first users of the multiple access facility will be a group at the Atlas laboratory working on artificial intelligence, the group concerned with the statistical planning system known as ASCOT, and a scheme to use multiple access for information retrieval within the Culham Laboratory.

The laboratory itself seems now to have settled down in the building at Culham, Berkshire, which it has occupied since the middle of 1964. At present the computer is running three shifts on five days a week, and the weekends are likely to be used as well in the course of this year. The computer itself is now in service for between 95 and 98 per cent of the available time, and half of the unplanned shutdowns seem to be due to failures in the $48 \mathrm{~K}$ core store with which the machine is provided. The experience of the past few months has shown that, in a typical week, something like 2,500 jobs may be undertaken at the laboratory. The principal customers are universities, and there are 250 university projects on the book, most of them in mathematics, the physical sciences and engin. eering. The laboratory also works for some industria? users and for government research laboratories. It has, for example, been concerned with numerical fore casting for the Meteorological Office.

\section{Feeling the Pinch}

Federal support for science was the theme when Dr. Frederick Seitz, President of the National Academy of Sciences, dedicated the Space Sciences Building at the University of Arizona in Tucson. Dr. Seitz gave the impression that research workers were beginning to go short of money, and the war in Vietnam was not the only reason for this. For a start, expenditure on basic science was not growing at the rate of 15 per cent per year which many people felt was necessary. The figure of 15 per cent, he said, applied only to basic sciences, and only for a limited period, perhaps a decade or so more.

The second difficulty was that of big science. The Mohole project, said Dr. Seitz, had been scientifically sound, but had been cancelled because of the escalation of costs and the intrusion of political issues. Dr. Seitz said that he hoped the project would be reinstated; a permanent restriction on deep-sea drilling would not serve the interests of science. As for the $200 \mathrm{GeV}$ accelerator, which scientists in the United States had asked for, Congress had not yet felt ready to act, while in the U.S.S.R. a $70 \mathrm{GeV}$ accelerator was almost finished and in Europe a $300 \mathrm{GeV}$ machine seriously contemplated. If the decision on the American machine were delayed beyond 1967, the position of the United States in high energy physics would be put in serious jeopardy.

A third factor, according to Dr. Seitz, was the growing geographical concentration of scientific expenditure. Centres of excellence, he implied, carried with them their own dangers in a country in which so many decisions are made on the basis of proportional representation. "It is difficult to believe that Congress will agree indefinitely both to expand the budgets for science and to concentrate the money increasingly in a few geographical areas." Congress might well take the matter of geographical distribution into its own hands. On space research, Dr. Seitz hoped that the frenzied atmosphere of competition could be replaced by some form of international co-operation to ensure that the scientific aspects of the exploration could be handled in a less peripheral way. 